\title{
MOLECULAR GENETIC CHARACTERIZATION OF BOTH COMPONENTS OF A DEDIFFERENTIATED CHONDROSARCOMA, WITH IMPLICATIONS FOR ITS HISTOGENESIS
}

\author{
JUDith V. M. G. BOVÉE ${ }^{1 *}$, ANNE-MARIE CLETON-JANSEN ${ }^{1}$, CARLA ROSENBERG ${ }^{2,3}$, ANTONIE H. M. TAMINIAU ${ }^{4}$, \\ CEES J. CORNELISSE ${ }^{1}$ AND PANCRAS C. W. HOGENDOORN ${ }^{1}$ \\ ${ }^{1}$ Department of Pathology, Leiden University Medical Centre, Leiden, The Netherlands \\ ${ }^{2}$ Laboratory of Cytochemistry and Cytometry, Department of Molecular Cell Biology, Leiden University Medical Centre, Leiden, \\ The Netherlands \\ ${ }^{3}$ Laboratory for Experimental Patho-Oncology, Daniel den Hoed Cancer Centre, University Hospital Rotterdam, Rotterdam, \\ The Netherlands \\ ${ }^{4}$ Department of Orthopaedic Surgery, Leiden University Medical Centre, Leiden, The Netherlands
}

\begin{abstract}
SUMMARY
Dedifferentiated chondrosarcoma is defined as a high-grade, anaplastic sarcoma adjacent to a low-grade malignant cartilage-forming tumour. Controversy remains as to whether the anaplastic and cartilaginous components are derived from a common precursor cell, or whether they represent separate genotypic lineages (collision tumour). Both components of a case of dedifferentiated chondrosarcoma were therefore separately investigated by loss of heterozygosity $(\mathrm{LOH})$ analysis, comparative genomic hybridization (CGH), DNA flow cytometry, and p53 analysis. Both showed p53 overexpression and an identical somatic 6 bp deletion in exon 7 of p53. Combination of the CGH and LOH results revealed that both components had lost the same copy of chromosome 13. These results provide compelling evidence in this case for a common origin, instead of the 'collision tumour' theory. Certain genotypic alterations were not shared. The anaplastic component showed severe aneuploidy, $\mathrm{LOH}$ at additional loci, and amplification and deletion of several chromosome parts. In contrast, the cartilaginous component had lost chromosomes 5, 22, 17p and part of $16 \mathrm{p}$ and revealed an amplification of 17q. The LOH and CGH results further demonstrated that the two components had lost a different copy of chromosome 4. Thus, a substantial number of genetic alterations have occurred after the diversion of the two components, indicating that the separation of the two clones, derived from a single precursor, was a relatively early event in the histogenesis of this case of dedifferentiated chondrosarcoma. Copyright (C) 1999 John Wiley \& Sons, Ltd.
\end{abstract}

KEY WORDS—-dedifferentiated chondrosarcoma; bone neoplasm; loss of heterozygosity; comparative genomic hybridization; p53

\section{INTRODUCTION}

The term dedifferentiated chondrosarcoma is applied to a high-grade sarcoma occurring next to a low-grade malignant cartilage-forming tumour; it comprises approximately 10 per cent of all chondrosarcomas. ${ }^{1}$ The tumour generally occurs after the age of 50 years, with males and females equally affected. ${ }^{2}$ It is most often located in the bones of the pelvis, the proximal femur or humerus, the distal femur, and the ribs. Regardless of treatment, the prognosis is ominous with 90 per cent of patients dying with distant metastases within 2 years. ${ }^{3}$

Microscopically, the junction between the cartilaginous and the non-cartilaginous anaplastic component is remarkably sharp. The non-cartilaginous component may express features of a malignant fibrous histiocytoma (MFH), osteosarcoma, fibrosarcoma, rhabdomyosarcoma or angiosarcoma, with MFH features most frequently present. In 25 per cent of cases, the

*Correspondence to: Judith V. M. G. Bovée, MD, Department of Pathology, Leiden University Medical Centre, PO Box 9600, L1-Q, 2300 RC Leiden, The Netherlands. E-mail: JBovee@Pat.azl.nl

Grant sponsor: Sacha Swarttouw-Hijmans Foundation.

Grant sponsor: Post Graduate School for Molecular Medicine, Leiden and Rotterdam. diagnosis is made at the time of local recurrence. ${ }^{2}$ Distant metastases usually consist solely of the highgrade anaplastic component.

Controversy remains as to whether the anaplastic and cartilaginous components are derived from a common precursor cell, ${ }^{4}$ or whether the anaplastic component represents a separate genotypic lineage (collision tumour)..$^{5-7} \mathrm{We}$ investigated both components of a case of dedifferentiated chondrosarcoma by loss of heterozygosity ( $\mathrm{LOH})$ analysis, comparative genomic hybridization (CGH), DNA flow cytometry, p53 immunohistochemistry, and p53 mutation analysis, in order further to elucidate the histogenesis of this rare entity.

\section{MATERIALS AND METHODS}

\section{Clinical information}

A 50-year-old female presented with a 6-month history of right sided hip complaints. Radiographs and CT scan revealed a large lytic lesion in the diaphysis of the proximal right femur, with intralesional calcifications and cortical thickening. MRI revealed intermediate signal intensity on the T1-weighted MR images and a high signal intensity on the T2-weighted MR images. 


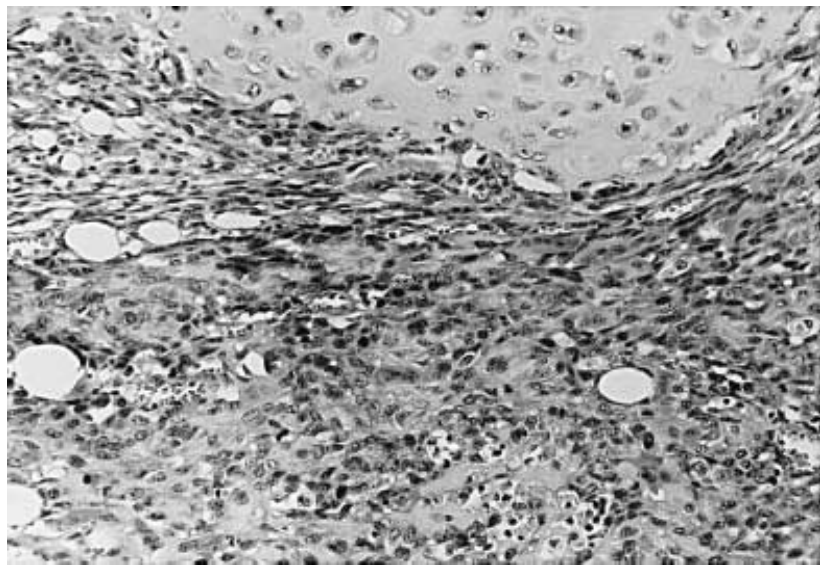

Fig. 1-Histological appearance of the primary resection specimen. Above, the moderately cellular cartilaginous component can be seen. The boundary between the two components is remarkably sharp. The anaplastic component showed a high-grade spindle cell tumour in which transformation to an osteosarcomatous phenotype was seen

Combined imaging features were therefore highly suggestive of a malignant cartilaginous tumour. A Jamshidi trocar biopsy was performed and histological examination revealed a chondrosarcoma grade II, according to Evans. ${ }^{8}$ Subsequent treatment consisted of resection of the tumour with reconstruction by inlay allograft. The resected specimen showed at cut surface a grey white glassy tumour within the proximal femur, with a length of $8.5 \mathrm{~cm}$. Routine sections demonstrated a moderately cellular chondroid tumour with binucleated cells and sporadic mitosis (grade II), next to a relatively small high-grade undifferentiated component in the proximal part of the resected specimen, reaching to the proximal osteotomy. This component showed a spindle cell phenotype and a high number of mitoses (up to 3 per HPF), in which focal transformation towards an osteosarcomatous phenotype was seen, with focal deposition of osteoid matrix surrounding the tumour cells. There was an abrupt margin between the cartilaginous and anaplastic areas (Fig. 1). The case was additionally evaluated by The Netherlands Committee on Bone Tumours and the diagnosis of dedifferentiated chondrosarcoma was supported after expert clinical-radiological and pathological review. Staging studies revealed no evidence of metastatic disease and adjuvant chemotherapy (adriamycin and cisplatin) was administered.

Six months later, the patient re-entered the clinic because of pain caused by tumour recurrence and a disarticulation of the right leg was performed. Histological examination revealed highly cellular undifferentiated tumour tissue with round-oval nuclei and scattered mitoses. CT scan demonstrated multiple lung metastases and the patient died 15 months after the first diagnosis.

\section{Specimens}

From the cartilaginous component, formalin-fixed, paraffin-embedded, and fresh frozen tumour tissue was obtained from the proximal femur resection. From the anaplastic component, formalin-fixed material was available. Fresh frozen tissue from this component was additionally derived from the amputation specimen.

\section{$D N A$ isolation}

DNA isolation from fresh frozen tissue, with tumour percentages estimated on cryostat sections to be more than 80 per cent, was performed using proteinase $\mathrm{K}$ treatment and phenol-chloroform extraction as previously described, ${ }^{9}$ with some modifications. Prior to proteinase $\mathrm{K}$ digestion, tumour tissue was pre-incubated in $3 \mathrm{M}$ sodium acetate buffer, $\mathrm{pH} 5 \cdot 6$, saturated with hyaluronidase for $2 \mathrm{~h}$ at $37^{\circ} \mathrm{C}$. The $\mathrm{pH}$ was then adjusted by adding $1 / 8$ volume of $2 \mathrm{~m}$ sodium hydroxide. Normal DNA from a freshly collected blood sample of the same patient was isolated using a salting-out procedure. ${ }^{10}$

\section{Loss-of-heterozygosity analysis}

Analysis of microsatellite markers was performed by polymerase chain reaction (PCR) on $100 \mathrm{ng}$ of DNA as described by Weber and May ${ }^{11}$ using $1 \mu \mathrm{Ci}$ of $\left[a^{32} \mathrm{P}\right] \mathrm{dCTP}$ in a total volume of $12 \mu \mathrm{l}$. Thermal cycling was performed in a programmable heatblock (MJ Research, Watertown, MA, U.S.A.) consisting of 27 cycles with an annealing temperature of $55^{\circ} \mathrm{C}$. The microsatellite markers used were selected because they map to chromosome regions reported to be involved in chondrosarcoma. Apart from primers in the EXT and $E X T$-like region, primers were chosen in the p53 12 and $\mathrm{Rb}^{12}$ region, at $9 \mathrm{p} 21,{ }^{13}$ and at $10 \mathrm{p} 15$ and $10 \mathrm{q} 11 .{ }^{14}$ Polymorphic markers are described in the Genome Database (http://gdbwww.gdb.org). Chromosomes 4, 13 , and 17 were investigated in detail using D4S230, D4S43, D4S189, D4S190, D4S1629, D4S231, D4S192, D4S175, D4S171, D4S194, ANT1, D13S175, D13S115, D13S217, FLT1, D13S220, D13S168, D13S124, D13S159, D13S173, D17S1532, D17S578, D17S520, D17S514, THRA1, D17S855, D17S1322, D17S1323, D17S1327, D17S579, D17S588, HOX2B, MPO, HGF, D17S1818, D17S1861, and D17S1692. After electrophoresis on a 6.5 per cent polyacrylamide gel containing $7 \mathrm{~m}$ urea, gels were dried and exposed to X-ray films. Signal intensities were measured by Phosphor Imaging (Molecular Dynamics, Sunyvale, CA, U.S.A.). LOH was scored when the quotient of the ratios of both alleles of normal and tumour was larger than or equal to $1 \cdot 7 .{ }^{15}$ Ratios between 1.3 and 1.7 were regarded as inconclusive. ${ }^{16}$

\section{Comparative genomic hybridization}

The CGH procedure was based on the protocol described by Kallioniemi et al., ${ }^{17}$ with a few modifications as described previously. ${ }^{18}$ Briefly, test DNA was directly labelled with FITC-dUTP and reference DNA was labelled with lissamine-dUTP (NEN LifeSciences, duPont), both by nick translation. Nick-translated fragment sizes ranged from 400 to $2000 \mathrm{bp}$. Two hundred nanograms of each labelled DNA and $10 \mu \mathrm{g}$ of Cot-1 
Table I-List of the microsatellite markers tested. Mean allelic imbalance ratios are given for both the cartilaginous and the anaplastic components. Ratios above 1.7 were considered as loss of heterozygosity and are in bold. Inconclusive ratios are given in italics

\begin{tabular}{|c|c|c|c|c|c|}
\hline Gene & Marker & $\begin{array}{c}\text { Chromosomal } \\
\text { localization }\end{array}$ & $\begin{array}{l}\text { Hetero- } \\
\text { zygosity }\end{array}$ & $\begin{array}{l}\text { Cartilaginous } \\
\text { component }\end{array}$ & $\begin{array}{l}\text { Anaplastic } \\
\text { component }\end{array}$ \\
\hline \multirow[t]{4}{*}{ EXT1 } & D8S85 & $8 \mathrm{q} 23.3$ & 0.74 & 1 & 1 \\
\hline & D8S547 & $8 \mathrm{q} 24.11$ & 0.66 & n.i. & n.i. \\
\hline & D8S522 & $8 \mathrm{q} 24.12-13$ & 0.71 & n.i. & n.i. \\
\hline & D8S198 & $8 \mathrm{q} 24.13$ & 0.83 & 1 & 1 \\
\hline \multirow[t]{3}{*}{ EXT2 } & D11S905 & $11 \mathrm{p} 13-\mathrm{p} 12$ & 0.74 & $1 \cdot 12$ & 1.54 \\
\hline & D11S903 & $11 \mathrm{p} 13-\mathrm{q} 13$ & 0.74 & 1 & 1 \\
\hline & D11S554 & $11 \mathrm{p} 11.2-12$ & $0 \cdot 91$ & 1 & $1 \cdot 77$ \\
\hline \multirow[t]{3}{*}{ EXT3 } & D19S216 & 19 pter-qter & 0.75 & $1 \cdot 11$ & $1 \cdot 08$ \\
\hline & D19S413 & 19pter-qter & $0 \cdot 76$ & n.i. & n.i. \\
\hline & D19S221 & $19 \mathrm{p} 13.2$ & $0 \cdot 86$ & 1 & 1 \\
\hline \multirow[t]{2}{*}{ EXTL1 } & D1S436 & $1 \mathrm{p} 36$ & $0 \cdot 75$ & $1 \cdot 14$ & $1 \cdot 33$ \\
\hline & D1S470 & $1 \mathrm{p} 36$ & $0 \cdot 76$ & $1 \cdot 04$ & $1 \cdot 48$ \\
\hline \multirow{2}{*}{ EXTL2 } & D1S206 & $1 \mathrm{p} 11-12$ & $0 \cdot 82$ & $1 \cdot 06$ & $1 \cdot 28$ \\
\hline & D1S248 & $1 \mathrm{p} 11-12$ & $0 \cdot 82$ & n.i. & n.i. \\
\hline \multirow[t]{4}{*}{ EXTL3 } & D8S1130 & $8 \mathrm{p} 12-\mathrm{p} 22$ & $0 \cdot 93$ & $1 \cdot 12$ & $3 \cdot 3$ \\
\hline & gata119c & $8 \mathrm{p} 12-\mathrm{p} 21$ & & n.i. & n.i. \\
\hline & D8S1820 & $8 \mathrm{p}$ & $0 \cdot 73$ & $1 \cdot 08$ & $3 \cdot 27$ \\
\hline & D8S283 & $8 \mathrm{p}$ & $0 \cdot 78$ & $1 \cdot 05$ & $2 \cdot 92$ \\
\hline \multirow[t]{2}{*}{ p53 } & TP 53 & $17 \mathrm{p} 13.1$ & 0.69 & $4 \cdot 69 \uparrow$ & $2 \cdot 91 \uparrow$ \\
\hline & D17S513 & $17 \mathrm{p} 13.3$ & $0 \cdot 89$ & $7 \cdot 6 \uparrow$ & $4 \cdot 8 \uparrow$ \\
\hline \multirow[t]{2}{*}{$\mathrm{Rb}$} & D13S153 & $13 q 14.1-14.3$ & $0 \cdot 82$ & $4 \cdot 8 \uparrow$ & $3.96 \uparrow$ \\
\hline & D13S155 & 13q14.3-q21.2 & $0 \cdot 83$ & $3 \cdot 55 \downarrow$ & $2 \cdot 02 \downarrow$ \\
\hline \multirow[t]{3}{*}{ 10p15 } & D10S559 & 10pter-p11.2 & $0 \cdot 80$ & n.i. & n.i. \\
\hline & D10S1435 & $10 \mathrm{p}$ & $0 \cdot 32$ & $1 \cdot 01$ & $3 \cdot 3$ \\
\hline & D10S89 & $10 \mathrm{p}$ & & n.i. & n.i. \\
\hline \multirow[t]{6}{*}{$10 q 11$} & D10S604 & 10pter-qter & 0.66 & n.i. & n.i. \\
\hline & D10S538 & 10pter-qter & $0 \cdot 73$ & $1 \cdot 01$ & $2 \cdot 03$ \\
\hline & D10S109 & 10q11.2-qter & $0 \cdot 71$ & $1 \cdot 16$ & $2 \cdot 4$ \\
\hline & D10S110 & 10q11.2-qter & $0 \cdot 58$ & n.i. & n.i. \\
\hline & D10S185 & $10 \mathrm{q} 23-24$ & $0 \cdot 77$ & $1 \cdot 05$ & $2 \cdot 01$ \\
\hline & D10S575 & $10 q 26$ & $0 \cdot 63$ & $1 \cdot 1$ & 2.1 \\
\hline \multirow[t]{2}{*}{$9 \mathrm{p} 21$} & D9S43 & $9 \mathrm{p} 21$ & $0 \cdot 83$ & $1 \cdot 1$ & \\
\hline & D9S171 & $9 \mathrm{p} 21$ & $0 \cdot 80$ & $1 \cdot 03$ & $1 \cdot 27$ \\
\hline
\end{tabular}

n.i. $=$ non-informative (homozygous) at the locus; $\uparrow=$ upper allele lost; $\downarrow=$ lower allele lost.

DNA were hybridized to normal male metaphases and incubated at $37^{\circ} \mathrm{C}$ for 4 days. Post-hybridization washes were performed with $2 \times \mathrm{SSC}$ at $37^{\circ} \mathrm{C}$, followed by $0 \cdot 1 \times \mathrm{SSC}$ at $60^{\circ} \mathrm{C}$. Slides were counterstained with DAPI in an antifade solution. Digital images were analysed using QUIPS XL software from Vysis (Downers Grove, IL, U.S.A.). Losses of DNA sequences were defined as chromosomal regions where the average green-to-red ratio and its 95 per cent confidence interval are below $0 \cdot 9$, and gains above $1 \cdot 1$. These threshold values were based on measurements from a series of normal controls.

\section{DNA flow cytometry}

Single cell suspensions from fresh frozen tissue for single-parameter nuclear DNA flow cytometry (FCM) were prepared by the method of Vindelov et al. ${ }^{19}$ and measured on a FACSCalibur flow cytometer (Becton Dickinson, Mountain View, CA, U.S.A.). Trout red blood cells served as an internal standard for determi- nation of the G1 cell DNA content. ${ }^{20}$ ModFitLT V2.0 software was used for data acquisition. DNA histograms were evaluated according to accepted criteria. $^{21}$

\section{Immunohistochemistry}

Monoclonal antibodies directed to Ki-67, clone MIB1 (Immunotech SA, Marseilles, France) and p53, clone DO-7 (DAKO, Glostrup, Denmark) were used. Immunohistochemical reactions were performed on formalinfixed, paraffin-embedded tumour sections according to standard laboratory methods. ${ }^{22}$ As a negative control, slides were incubated with phosphate-buffered saline containing 1 per cent bovine serum albumin, instead of primary antibodies. Positive controls included a normal tonsil for Ki-67 and a p53-positive colorectal carcinoma for p53. Ki-67-positive nuclei were counted per 200 tumour cells, in areas containing the largest number of positive cells. 
Table 2-Loss of heterozygosity analysis on chromosomes 4 13 , and 17 was performed using markers spanning the whole chromosome. Only heterozygous markers are shown. Allelic imbalance ratios are given for both the cartilaginous and the anaplastic component

\begin{tabular}{|c|c|c|c|}
\hline Marker & $\begin{array}{c}\text { Chromosomal } \\
\text { localization }\end{array}$ & $\begin{array}{l}\text { Cartilaginous } \\
\text { component* }\end{array}$ & $\begin{array}{l}\text { Anaplastic } \\
\text { component* }\end{array}$ \\
\hline D4S174 & $4 p 21.1-p 14$ & $6 \cdot 34 \uparrow$ & $\mathbf{2 \cdot 8 0} \downarrow$ \\
\hline D4S230 & 4pter-p15 & $6 \cdot 63 \uparrow$ & $3 \cdot 64 \downarrow$ \\
\hline D4S43 & $4 \mathrm{p} 16.3$ & $6 \cdot 27 \uparrow$ & $2 \cdot 94 \downarrow$ \\
\hline D4S190 & $4 \mathrm{p} 21.1-\mathrm{p} 14$ & $2 \cdot 19 \uparrow$ & $1 \cdot 77 \downarrow$ \\
\hline D4S1629 & 4pter-qter & $6 \cdot 34 \uparrow$ & $3 \cdot 19 \downarrow$ \\
\hline D4S192 & $4 q 25-34$ & $5 \cdot 82 \uparrow$ & $3.50 \downarrow$ \\
\hline D4S175 & $4 q 31$ & $7 \cdot 12 \uparrow$ & $2 \cdot 72 \downarrow$ \\
\hline ANT1 & $4 q 35$ & $3 \cdot 63 \downarrow$ & $2 \cdot 90 \uparrow$ \\
\hline D13S115 & $13 q 11-12.1$ & $3 \cdot 75 \uparrow$ & $\mathbf{2} \cdot \mathbf{7 0} \uparrow$ \\
\hline FLT1 & $13 \mathrm{q} 12$ & $5 \cdot 47 \uparrow$ & $3 \cdot 37 \uparrow$ \\
\hline D13S153 & $13 \mathrm{q} 14.1-\mathrm{q} 14.3$ & $4 \cdot 8 \uparrow$ & $3 \cdot 96 \uparrow$ \\
\hline D13S155 & $13 \mathrm{q} 14.3-\mathrm{q} 21.2$ & $2 \downarrow$ & $2 \downarrow$ \\
\hline D13S168 & $13 \mathrm{q} 14.3$ & $7 \cdot 03 \uparrow$ & $4 \cdot 75 \uparrow$ \\
\hline D13S159 & $13 q 32$ & $6.99 \downarrow$ & $2 \cdot 98 \downarrow$ \\
\hline D17S513 & $17 \mathrm{p} 13.3$ & $7 \cdot 6 \uparrow$ & $4 \cdot 8 \uparrow$ \\
\hline TP 53 & $17 \mathrm{p} 13.1$ & $4 \cdot 69 \uparrow$ & $2.91 \uparrow$ \\
\hline D17S520 & $17 \mathrm{p} 12$ & $8 \cdot 66 \downarrow$ & $3 \cdot 88 \downarrow$ \\
\hline THRA1 & $17 q 11.1-q 12$ & $15 \cdot 67 \uparrow$ & $8 \cdot 17 \uparrow$ \\
\hline D17S855 & $17 \mathrm{q} 21$ & $1.77 \downarrow$ & $4 \cdot 19 \uparrow$ \\
\hline D17S588 & $17 \mathrm{q}$ & $1 \cdot 69 \uparrow$ & $3 \cdot 57 \downarrow$ \\
\hline
\end{tabular}

$\uparrow=$ upper allele lost; $\downarrow=$ lower allele lost.

* Ratios above 1.7 were considered as $\mathrm{LOH}$ and are in bold. Inconclusive ratios are given in italics.

\section{p53 mutation analysis}

PCR for exons 5-8 of the p53 gene was performed on $100 \mathrm{ng}$ of DNA in a total volume of $25 \mu \mathrm{l}$ containing $12.5 \mathrm{pmol}$ of the forward and $12.5 \mathrm{pmol}$ of the reverse primer, 1 per cent BSA, $0 \cdot 01$ per cent gelatin, $0 \cdot 1$ per cent Triton X-100, $10 \mathrm{~mm}$ Tris- $\mathrm{HCl}$ ( $\mathrm{pH} 9 \cdot 0), 50 \mathrm{~mm}$ $\mathrm{KCl}, 1.5 \mathrm{mM} \mathrm{MgCl} 2,0.2 \mathrm{~mm} \mathrm{dNTP}$, and $0.06 \mathrm{U}$ of
SuperTaq DNA polymerase (Sphaero Q, HT Biotechnology Ltd., Cambridge, U.K.). The primers used for amplification were: exon 5 forward: TTCCTCTTCCT GCAGTACTC, reverse: TCTCTGCTGTCCCGACC AAC; exon 6 forward: TGGGGCTGGAGAGACGAC, reverse: AGGGATATTGGGGTACTCTACAC; exon 7 forward: GTGTTATCTCCTAGGTTGGC, reverse: AGGTCCAGTCCTCGGTGAAC; exon 8 forward: TGATTTCCTTACTGCCTCTTG, reverse: CACGTCAATACGGAGTCTAA. Thermal cycling was performed in a programmable heatblock (Perkin Elmer Cetus, Norwalk, CT, U.S.A.) using a 'touchdown' PCR program of 47 cycles consisting of two cycles with annealing at $65^{\circ} \mathrm{C}$, two cycles at $64^{\circ} \mathrm{C}$, two cycles at $63^{\circ} \mathrm{C}$, two cycles at $62^{\circ} \mathrm{C}$, two cycles at $61^{\circ} \mathrm{C}$, two cycles at $60^{\circ} \mathrm{C}$, four cycles at $59^{\circ} \mathrm{C}$, six cycles at $58^{\circ} \mathrm{C}$, and 25 cycles at $57^{\circ} \mathrm{C}$. PCR products were purified using MicroSpin G-50 columns (Pharmacia Biotech, Uppsala, Sweden). Subsequent sequencing reactions were performed using the ABI Prism BigDye Terminator Cycle Sequencing Ready Reaction Kit, according to the manufacturer's recommendations (Perkin Elmer Applied Biosystems, Foster City, CA, U.S.A.). Samples were run on the ABI 377 semi-automated sequencer (Perkin Elmer, The Netherlands). Both strands were sequenced.

\section{RESULTS}

\section{Loss of heterozygosity ( $\mathrm{LOH}$ )}

The cartilaginous component demonstrated $\mathrm{LOH}$ at $17 \mathrm{p} 13,13 \mathrm{q} 14$, and chromosome 4 (Tables I and II). The anaplastic component demonstrated loss of the same alleles on $17 \mathrm{p} 13$ and $13 \mathrm{q} 14$ and, additionally, LOH was detected on chromosomes 8,10 , and 11 . LOH at chromosome 4 was also identified, but involved the other allele than in the cartilaginous component (Table II). This phenomenon involved all markers tested, spanning chromosome 4 . For all markers spanning chromosome 13, the same allele was lost in both components. On

\section{D4S174 D10S538 D13S153 TP53 THRA1 D17S855}

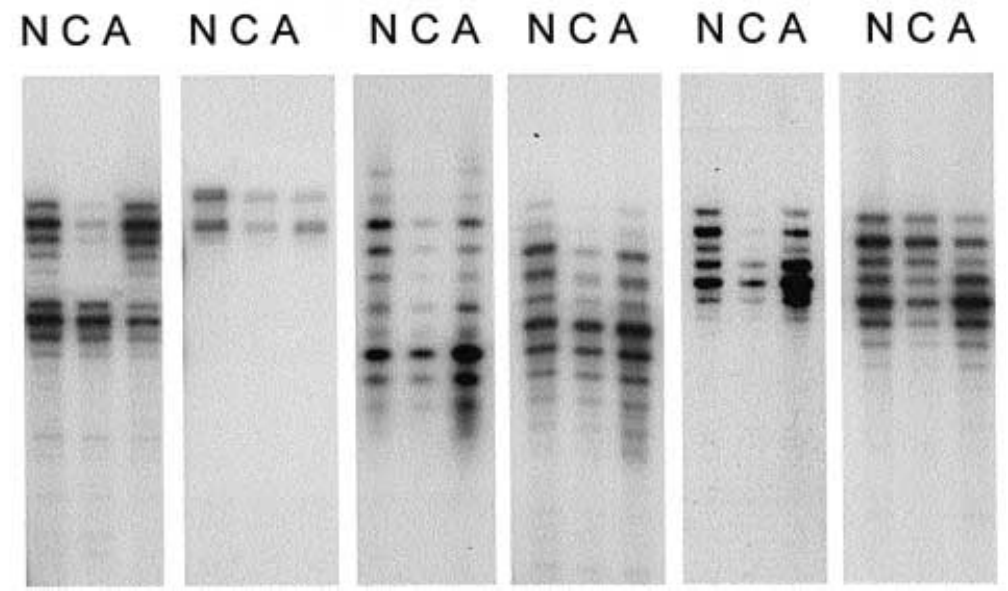

Fig. 2-Examples of autoradiograms. Microsatellite markers are indicated above each panel. $\mathrm{N}=$ normal DNA; $\mathrm{C}=$ cartilaginous component; $\mathrm{A}=$ anaplastic component. Allelic imbalance ratios are given in Tables I and II 


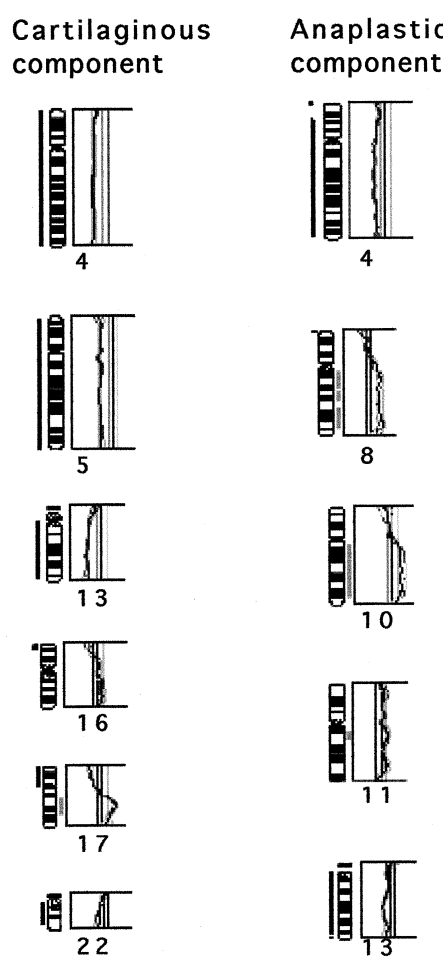

Fig. 3-Examples of unbalances found by CGH analyses in the cartilaginous and anaplastic components. The profiles show the average fluorescence intensity ratios and its 95 per cent confidence interval. Over- and under-representations are shown as grey bars on the right and black bars on the left sides of the ideograms, respectively.

chromosome 17, both components showed loss of the same allele for markers located on the short arm and the centromeric part of the long arm, whereas on the rest of the long arm, different alleles were lost in the two components, with relatively low allelic imbalance ratios in the cartilaginous component (Table II). Examples are shown in Fig. 2.

\section{Comparative genomic hybridization}

The cartilaginous component was characterized by the deletion of chromosomes 4, 5, 13, 22 and the distal part
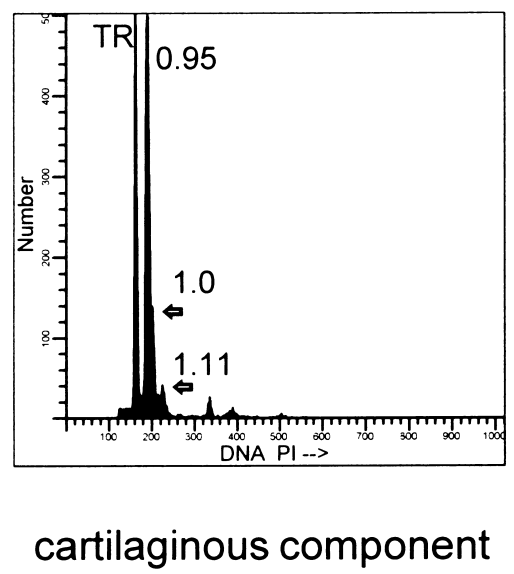

of chromosome $16 \mathrm{p}$. Chromosome 17 revealed a deletion: del(17)(pter-q12) and an amplification on the long arm. In contrast, the anaplastic component demonstrated amplification on $2 \mathrm{p}, 8 \mathrm{q}, 10 \mathrm{q}, 11 \mathrm{q}, 12 \mathrm{p}, 12 \mathrm{q}, 19 \mathrm{p}$, and possibly on $1 \mathrm{p}$. Deletion was seen on $2 \mathrm{q}, 4,5 \mathrm{q}, 13$, Xp, and Xq (Fig. 3).

\section{Flow cytometry}

Flow cytometric analysis demonstrated two peridiploid clones in the cartilaginous component, with DNA indices of 0.95 and $1 \cdot 11$. The anaplastic component revealed two highly aneuploid clones of 1.60 and $2 \cdot 84$ respectively (Fig. 4 ).

\section{Immunohistochemistry}

p53 immunoreactivity was seen in both components present in the primary tumour (Figs 5A and 5B), as well as in the anaplastic component of the recurrence. Proliferative activity in the primary tumour was higher in the anaplastic component than in the cartilaginous component (45 per cent versus 16 per cent Ki-67-positive cells), whereas in the recurrence specimen, 75 per cent positive cells were found.

\section{p53 mutation analysis}

Mutation analysis revealed a $6 \mathrm{bp}$ deletion (CCATCC) starting at the second base of codon 250 in exon 7 in both the cartilaginous and the anaplastic component which was absent in normal DNA of the patient (Figs 5C and 5D). The deletion leads to the elimination of the amino acids proline and isoleucine from the central DNA-binding domain of the p53 protein.

\section{DISCUSSION}

In 1971, Dahlin and Beabout first described dedifferentiated chondrosarcoma as a rare variant within the

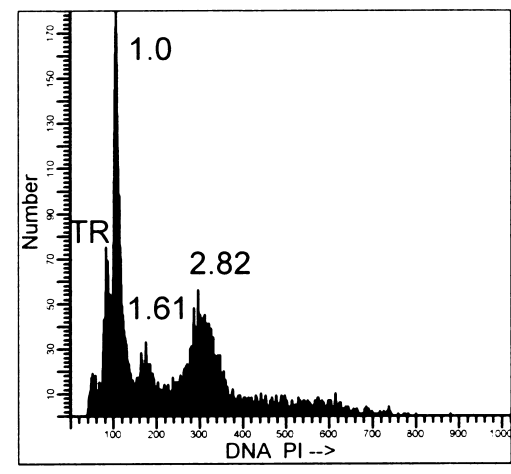

anaplastic component

Fig. 4-Flow cytometric DNA histograms from nuclear suspensions of both the cartilaginous and the anaplastic component. Both demonstrate two different tumour cell clones, the cartilaginous component with peri-diploid DNA indices and the anaplastic component with highly aneuploid DNA indices. 
(A)

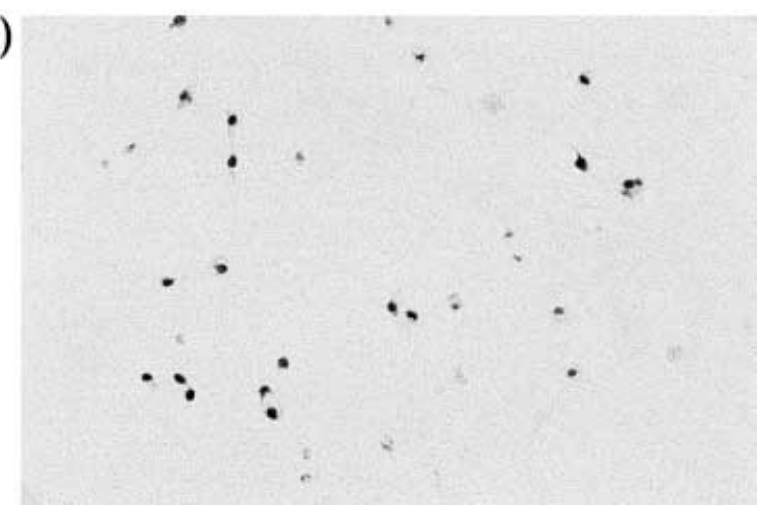

(C)

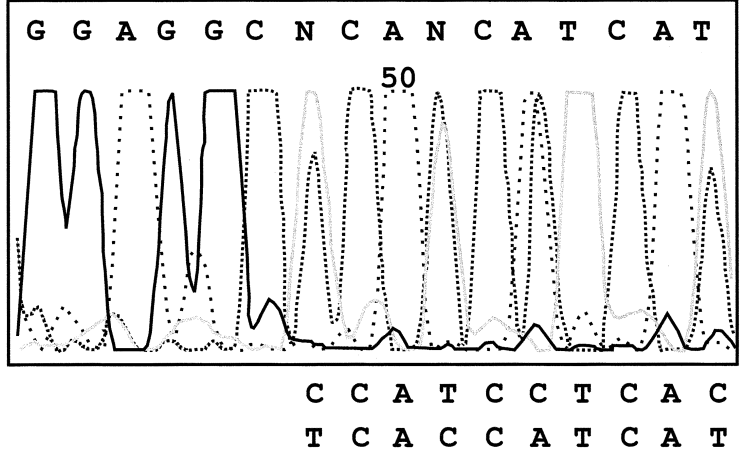

(B)
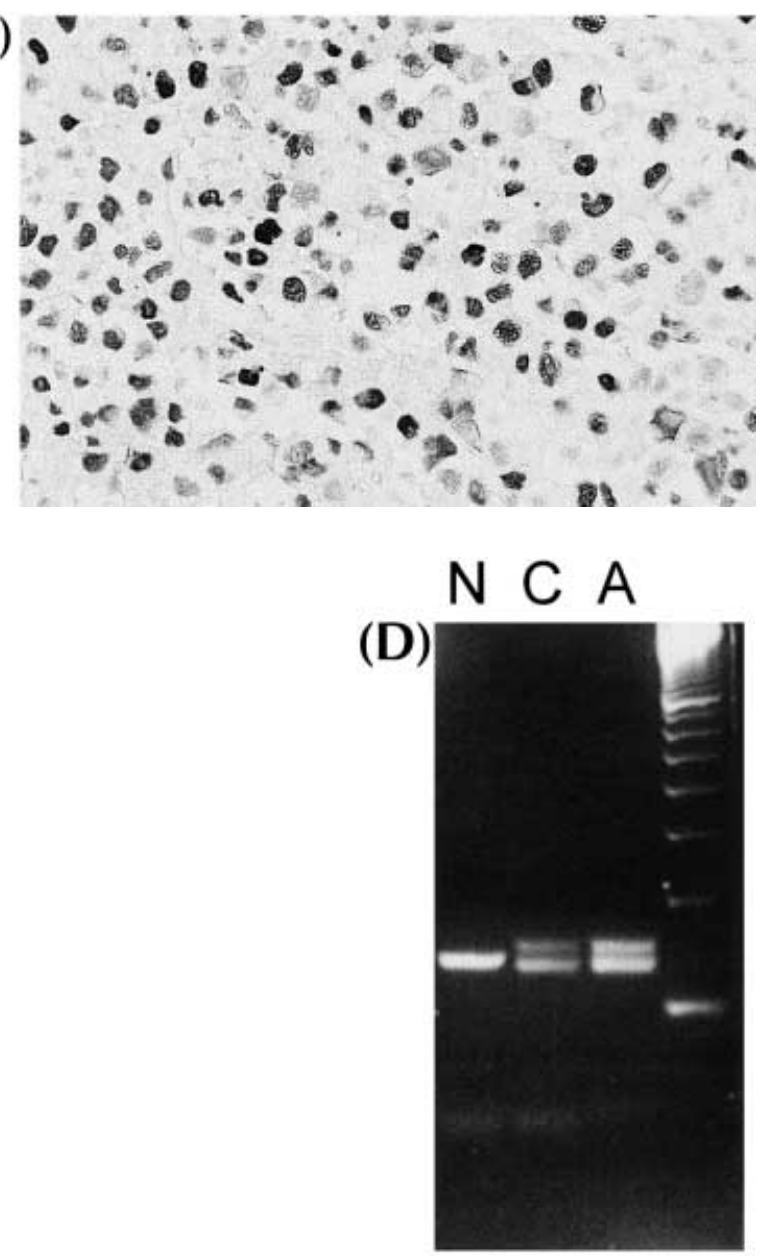

Fig. 5-p53 immunoreactivity was detected in both the cartilaginous (A) and the anaplastic (B) component. Sequencing results of exon 7 revealed a 6 bp deletion which was found in both components and not in DNA derived from peripheral blood (C). Starting at nucleotide 749, the second base of codon 250, two sequences running through each other can be detected and are indicated below. The upper sequence is the wild type, whereas the lower is the mutated sequence. PCR products of exon 7 were run on an agarose gel containing 3 per cent NuSieve GTG combined with 1 per cent Seakem GTG (both purchased from FMC BioProducts, Rockland, Maine, U.S.A.) (D). The 6 bp deletion was confirmed in both the cartilaginous and the anaplastic component and was not present in the germline

spectrum of malignant cartilaginous tumours. They explained the co-existence of the cartilaginous and anaplastic components as dedifferentiation of a welldifferentiated cartilaginous tumour cell to a primitive undifferentiated tumour cell ${ }^{23}$ (Fig. 6A). Sanerkin and Woods explained the presence of the anaplastic component as an independently developing sarcoma, arising within the reactive fibrous tissue surrounding necrotic areas in a pre-existing benign cartilaginous lesion. ${ }^{7}$ Since both components would then arise within different tissues, dedifferentiated chondrosarcoma should be referred to as a 'collision' tumour (Fig. 6B). Currently, the generally supported hypothesis is that high-grade elements represent a failure of differentiation, rather than dedifferentiation of mature chondroid cells. $^{6,24}$ It is still debated as to whether the two components are derived from two separate clones of cells (collision tumour) ${ }^{5,6}$ (Fig. 6B), or whether both components arise from a common primitive mesenchymal cell progenitor, possessing both the ability to differentiate and express chondrocytic features and the ability to express features of high-grade sarcomas ${ }^{4}$ (Fig. 6C).

Phenotypic characteristics of both components have been studied intensively by electron microscopy and immunohistochemistry. Most ultrastructural studies revealed the lack of chondroid features in the anaplastic component. ${ }^{6,25,26}$ Sparse S-100 protein-positive cells in the anaplastic component were interpreted as reflecting a retained potential for primitive chondrogenesis. ${ }^{26,27}$ An immunohistochemical study for collagen subtypes and cartilage proteoglycans indicated a non-chondrocytic nature of the anaplastic component, favouring the "collision tumour' theory. ${ }^{28}$ Since these studies are based on phenotypically reversible features, they do not provide evidence for the histogenesis of dedifferentiated chondrosarcoma, in contrast to studies investigating irreversible, fixed molecular genetic alterations.

Comparative molecular genetic studies of both components of dedifferentiated chondrosarcoma are sparse. Cytogenetic analysis was performed in eight cases ${ }^{4,29-33}$ and characteristic alterations have not been demon- 
A.

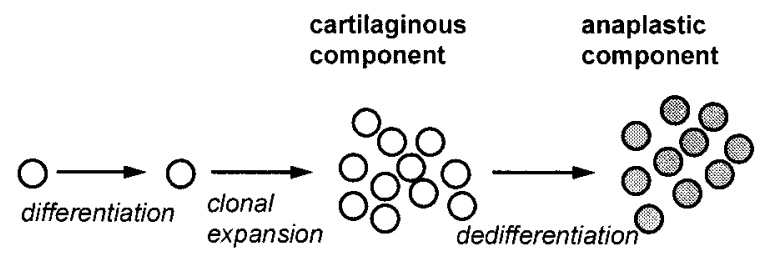

dedifferentiation
B.

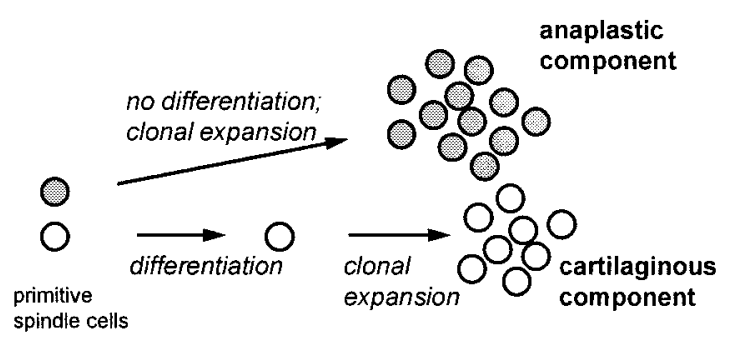

collision tumor
C.

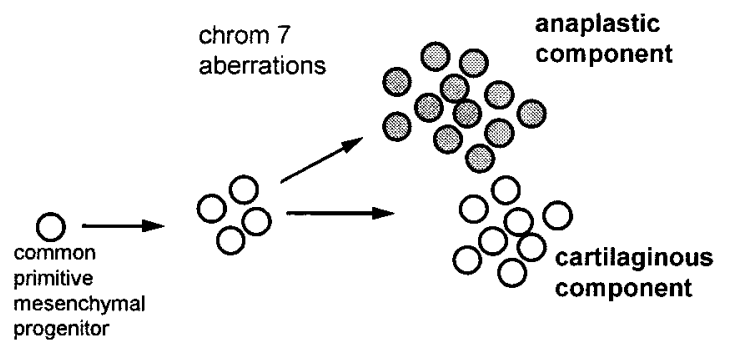

D.

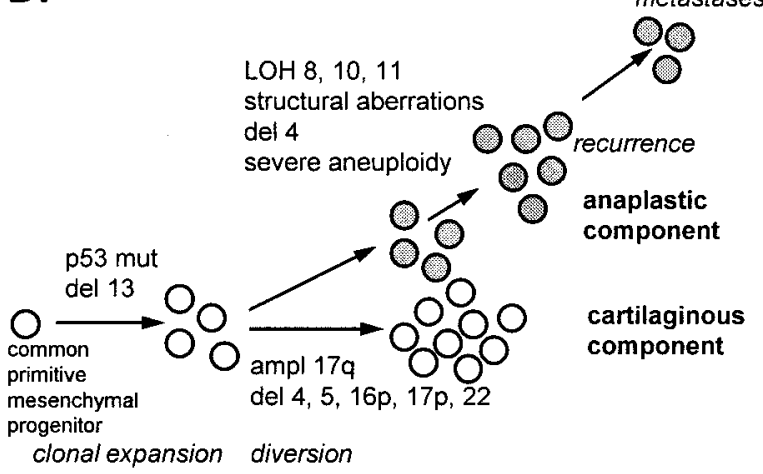

present study: monoclonal origin and early diversion

monoclonal origin?

Fig. 6-Theories of the histogenesis of dedifferentiated chondrosarcoma. (A) Originally it was thought that a well-differentiated cartilaginous tumour cell dedifferentiates into a primitive undifferentiated tumour cell. ${ }^{23}$ (B) The two components are derived from two separate clones of cells (collision tumour), one of which differentiates into a low-grade chondrosarcoma, while the other fails to differentiate and displays features of high-grade sarcoma. ${ }^{5,6,28}$ (C) Both components of dedifferentiated chondrosarcoma display numerical aberrations of chromosome $7,{ }^{4}$ suggesting that both components are derived from a single abnormal clone or cell. (D) The present case provides compelling evidence for a monoclonal origin, since both components have specific genetic alterations in common. However, the presence of many additional different genetic alterations suggests that the separation of the two clones was a relatively early event

strated. Most karyotypes are probably derived from the anaplastic component, overgrowing the slowly dividing cartilaginous component in tissue culture. Bridge et al. were the first to combine cytogenetic analysis with immunophenotyping and showed numerical aberrations of chromosome 7 in both components of dedifferentiated chondrosarcoma,${ }^{4}$ which would suggest that both were derived from a single abnormal clone or cell. However, it cannot be completely ruled out that both components independently obtained an extra chromosome 7. Extra copies of chromosome 7 were seen in three other cases, ${ }^{30,32,33}$ while CGH analysis of the present case did not show copy number changes of chromosome 7.

The results of the present case provide strong evidence to support a common origin. In both components, we identified an identical $6 \mathrm{bp}$ deletion in p53 which was not reported in a p53 mutation database (http:// p53.genome.ad.jp) and is therefore not regarded as a mutational hotspot. This provides strong evidence for a monoclonal origin and excludes a collision tumour in this case of dedifferentiated chondrosarcoma (Fig. 6D). Furthermore, $\mathrm{LOH}$ at $17 \mathrm{p}$ and 13 involved the same alleles.

However, we also found clear genetic differences. The anaplastic component showed LOH at additional loci that were not involved in the cartilaginous component (11p11.2-12, 8p, and chromosome 10), and amplification and deletion of several chromosome parts as demonstrated by CGH. In contrast, the cartilaginous component had lost chromosomes 5, 22, and the tip of $16 \mathrm{p}$ and revealed an amplification on 17q. Although at $17 \mathrm{p}$ both components lost the same alleles for all microsatellite markers tested, CGH analysis revealed a deletion of $17 \mathrm{p}$ in the cartilaginous component only. $\mathrm{LOH}$ analysis further revealed that both components 
had lost a different copy of chromosome 4. Moreover, the DNA indices indicate that it is unlikely that simple polyploidization of the 0.95 and 1.11 clone of the cartilaginous component has occurred in the anaplastic component, with DNA indices 1.60 and $2 \cdot 84$. Thus, our data show that many genetic alterations have occurred after the diversion of the two components and therefore suggest that the separation of the two clones was a relatively early event in the histogenesis of this dedifferentiated chondrosarcoma (Fig. 6D). This early separation may explain why many studies on the phenotypically reversible features of the two components demonstrated very different phenotypes, leading to the conclusion that dedifferentiated chondrosarcoma is a collision tumour. ${ }^{6,7,25,26,28}$ It remains unclear, however, whether (primitive) chondroid features are expressed before the divergence of the two components, supporting the original idea of 'dedifferentiation', or after the separation of the two lines of differentiation.

Since fresh-frozen tumour tissue of the anaplastic component was derived from the tumour recurrence specimen, we cannot completely rule out the possibility that some of the alterations detected in the anaplastic component are additional aberrations of the recurrence that occurred in the course of tumour progression. Unfortunately, DNA extracted from formalin-fixed, paraffin-embedded decalcified bone tumour tissue most often fails in PCR amplification and comparative genomic hybridization.

The p53 alteration being an early event in chondrosarcomas is in contrast with the literature, since p53 overexpression and mutation are mainly found in high-grade chondrosarcomas. ${ }^{12,34,35}$ Previously, p53 overexpression was reported in four dedifferentiated chondrosarcomas in the anaplastic component, ${ }^{34}$ whereas only focal weak positivity was noted in the cartilaginous areas. In another case, no immunoreactivity was seen in the cartilaginous component and in a fibrosarcomatous component, while a MFH-like portion demonstrated strong immunoreactivity. A missense mutation (Arg $\rightarrow \mathrm{Thr}$ in codon 249 of exon 7) was only found in DNA from the p53-positive area and was absent in the p53-negative specimens, ${ }^{36}$ suggesting that in this case, p53 was involved after the divergence of the two components. The presence of p53 overexpression and mutation in both components of the present case may be explained by the fact that the cartilaginous component was grade II according to Evans, ${ }^{8}$ while most dedifferentiated chondrosarcomas reported display a grade I cartilaginous component, as originally defined. ${ }^{23}$ Capanna et al. showed, however, that the cartilaginous component was of moderate to high histological grade in 25 of 46 (54 per cent) dedifferentiated chondrosarcomas. $^{3}$

In conclusion, the molecular genetic characterization of this case of dedifferentiated chondrosarcoma provides strong evidence for a monoclonal origin, since both components share an identical p53 mutation and deletion of the same copies of chromosome 13. Many different genetic alterations were also demonstrated, which occurred after the diversion of the two components. These results suggest that the separation of the two clones may be an early event in the histogenesis of dedifferentiated chondrosarcoma.

\section{ACKNOWLEDGEMENTS}

We would like to thank N. J. Kuipers-Dijkshoorn, L. J. C. M. van den Broek, E. Geelen, and A. M. Kersenmaekers for expert technical assistance and Dr F. Graadt van Roggen for critically reading the manuscript. This study was financially supported by the Sacha Swarttouw-Hijmans Foundation and the Post Graduate School for Molecular Medicine.

\section{REFERENCES}

1. Dorfman HD, Czerniak B (eds). Bone Tumors. Mosby: St Louis, 1998

2. Huvos AG (ed.). Bone Tumors. Diagnosis, Treatment, and Prognosis (2nd edn). W. B. Saunders: Philadelphia, 1991.

3. Capanna R, Bertoni F, Bettelli G, et al. Dedifferentiated chondrosarcoma. $J$ Bone Joint Surg [Am] 1988; 70A: 60-69.

4. Bridge JA, DeBoer J, Travis J, et al. Simultaneous interphase cytogenetic analysis and fluorescence immunophenotyping of dedifferentiated chondrosarcoma; implications for histopathogenesis. Am J Pathol 1994; 144: 215 220.

5. Rywlin AM, Robb JA. Chondrosarcoma of bone with 'dedifferentiation'. Hum Pathol 1982; 13: 963-964.

6. Tetu B, Ordonez NG, Ayala AG, Mackay B. Chondrosarcoma with additional mesenchymal component (dedifferentiated chondrosarcoma) II. An immunohistochemical and electron microscopic study. Cancer 1986; 58: 287-298.

7. Sanerkin NG, Woods CG. Fibrosarcomata and malignant fibrous histiocytomata arising in relation to enchondromata. J Bone Joint Surg $[\mathrm{Br}]$ 1979; 61B: 366-372.

8. Evans HL, Ayala AG, Romsdahl MM. Prognostic factors in chondrosarcoma of bone. A clinicopathologic analysis with emphasis on histologic grading. Cancer 1977; 40: 818-831.

9. Devilee P, Van den Broek M, Kuipers-Dijkshoorn N, et al. At least four different chromosomal regions are involved in loss of heterozygosity in human breast carcinoma. Genomics 1989; 5: 554-560.

10. Miller SA, Polesky HF. A simple salting out procedure for extracting DNA from human nucleated cells. Nucleic Acids Res 1988; 16: 1215.

11. Weber JL, May PE. Abundant class of human DNA polymorphisms which can be typed using the polymerase chain reaction. Am J Hum Genet 1989 ; 44: $388-396$.

12. Yamaguchi T, Toguchida J, Wadayama B, et al. Loss of heterozygosity and tumor suppressor gene mutations in chondrosarcomas. Anticancer Res 1996; 16: $2009-2016$.

13. Jagasia AA, Block JA, Qureshi A, et al. Chromosome 9 related aberrations and deletions of the CDKN2 and MTS2 putative tumor suppressor genes in human chondrosarcomas. Cancer Lett 1996; 105: 91-103.

14. Raskind WH, Conrad EU, Matsushita M. Frequent loss of heterozygosity for markers on chromosome arm 10q in chondrosarcomas. Genes Chromosomes Cancer 1996; 16: 138-143.

15. Gruis NA, Abeln ECA, Bardoel AFJ, Devilee P, Frants RR, Cornelisse CJ. PCR-based microsatellite polymorphisms in the detection of loss of heterozygosity in fresh and archival tumour tissue. Br J Cancer 1993; 68: 308-313.

16. Devilee P, Van Vliet M, Bardoel AFJ, et al. Frequent somatic imbalance of marker alleles for chromosome 1 in human primary breast carcinoma. Cancer Res 1991; 51: 1020-1025.

17. Kallioniemi O, Kallioniemi A, Piper $\mathbf{J}$, et al. Optimizing comparative genomic hybridization for analysis of DNA sequence copy number changes in solid tumors. Genes Chromosomes Cancer 1994; 10: 231-243.

18. Rosenberg C, Van Gijlswijk RPM, Vos CBJ, et al. Comparative genomic hybridization with lissamine- and fluorescein labelled nucleotides. Cytometry 1998; 32: 337-341.

19. Vindelov LL, Christensen IJ, Nissen NI. A detergent-trypsin method for the preparation of nuclei for flow cytometric DNA analysis. Cytometry 1983; 3 323-327.

20. Vindelov LL, Christensen IJ, Nissen NI. Standardization of high-resolution flow cytometric DNA analysis by the simultaneous use of chicken and trout red blood cells as internal reference standards. Cytometry 1983; 3: 328-331.

21. Hiddemann W, Schumann J, Andreef M, et al. Convention on nomenclature for DNA cytometry. Committee on Nomenclature, Society for Analytical Cytology. Cancer Genet Cytogenet 1984; 13: 181-183.

22. Bovee JVMG, Van den Broek LJCM, De Boer WI, Hogendoorn PCW. Expression of growth factors and their receptors in adamantinoma of long bones and the implications for its histogenesis. J Pathol 1998; 184: 24-30. 
23. Dahlin DC, Beabout JW. Dedifferentiation of low-grade chondrosarcomas. Cancer 1971; 28: 461-466.

24. Johnson S, Tetu B, Ayala AG, Chawla SP. Chondrosarcoma with additional mesenchymal component (dedifferentiated chondrosarcoma). I. A clinicopathologic study of 26 cases. Cancer 1986; 58: 278-286.

25. Kahn LB. Chondrosarcoma with dedifferentiated foci; a comparative and ultrastructural study. Cancer 1976; 37: 1365-1375.

26. Abenoza P, Neumann MP, Manivel JC, Wick MR. Dedifferentiated chondrosarcoma: an ultrastructural study of two cases, with immunocytochemical correlations. Ultrastruct Pathol 1986; 10: 529-538.

27. Wick MR, Siegal GP, Mills SE, Thompson RC, Sawhney D, Fechner RE. Dedifferentiated chondrosarcoma of bone; an immunohistochemical and lectin-histochemical study. Virchows Arch [A] 1987; 411: 23-32.

28. Aigner T, Dertinger S, Neureiter D, Kirchner T. De-differentiated chondrosarcoma is not a 'de-differentiated' chondrosarcoma. Histopathology 1998, 33: $11-19$.

29. Zalupski MM, Ensley JF, Ryan J, Selvaggi S, Baker LH, Wolman SR. A common cytogenetic abnormality and DNA content alterations in dedifferentiated chondrosarcoma. Cancer 1990; 66: 1176-1182.
30. Ozisik YY, Meloni AM, Peier A, et al. Cytogenetic findings in 19 malignant bone tumors. Cancer 1994; 74: 2268-2275.

31. Tarkkanen M, Wiklund T, Virolainen M, Elomaa I, Knuutila S. Dedifferentiated chondrosarcoma with $\mathrm{t}(9 ; 22)(\mathrm{q} 34 ; \mathrm{q} 11-12)$. Genes Chromosomes Cancer 1994; 9: 136-140.

32. Swarts SJ, Neff JR, Johansson SL, Bridge JA Cytogenetic analysis of dedifferentiated chondrosarcoma. Cancer Genet Cytogenet 1996; 89: 49-51.

33. Sawyer JR, Swanson CM, Lukacs JL, Nicholas RW, North PE, Thomas JR. Evidence of an association between 6q13-21 chromosome aberrations and locally aggressive behavior in patients with cartilage tumors. Cancer 1998; 82: 474 483.

34. Coughlan B, Feliz A, Ishida T, Czerniak B, Dorfman HD. p53 expression and DNA ploidy of cartilage lesions. Hum Pathol 1995; 26: 620-624.

35. Dobashi Y, Sugimura H, Sato A, et al. Possible association of p53 overexpression and mutation with high-grade chondrosarcoma. Diagn $\mathrm{Mol}$ Pathol 1993; 2: 257-263.

36. Wadayama B, Toguchida J, Yamaguchi T, Sasaki MS, Kotoura Y, Yamamuro T. p53 expression and its relationship to DNA alterations in bone and soft tissue sarcomas. Br J Cancer 1993; 68: 1134-1139. 